\title{
Serological diagnosis of cystic echinococcosis in cattle
}

\author{
Aitbay K. Bulashev, Zhanbolat A. Suranshiev, Orken S. Akibekov, Zhanara Zh. Akanova and \\ Gulmira A. Abulgazimova
}

Faculty of Veterinary and Livestock Technology, S. Seifullin Kazakh Agro-Technical University, Astana, Kazakhstan

\begin{abstract}
An IgM murine monoclonal antibody (MAb) was obtained against the excretory-secretory antigen (ES-Ag) of in vitro reared protoscoleces of Echinococcus granulosus (Batsch, 1786). Western blotting revealed that the MAb recognised a $20.6 \mathrm{kDa}$ protein of this ES-Ag. The MAb was used in sandwich enzyme-linked immunosorbent assay (s-ELISA) for selective sensitisation of the solid phase with the protoscolex-specific protein from its ES-Ag and somatic antigen (S-Ag) to examine serum samples of 108 cows from a cystic echinococcosis (CE) endemic area for specific antibodies and to compare the results with those from necropsies and an indirect ELISA (i-ELISA). The sensitivity of s-ELISA/ES-Ag, s-ELISA/S-Ag and i-ELISA/S-Ag was $48 \%, 52 \%$ and $62 \%$, respectively. The low sensitivity of the ELISA was probably caused by the fact that 13 cows $(62 \%)$ were infected with sterile cysts (acephalocysts and/or calcified foci) only. A relatively high specificity (80\%) of s-ELISA/ES-Ag was observed in cows with fertile cysts. It also detected antibodies in the serum of two cows that had recovered from the disease according to the necropsy. The i-ELISA/S-Ag gave false results in testing sera from a healthy animal and from a cow with tubercular foci. Further analysis will be necessary to define more precisely the value of this study, because the duration of antibody elimination from the bloodstream of recovered cattle remains unknown. The solution of this problem will increase the specificity of the proposed test in monitoring herbivorous animals for CE.
\end{abstract}

Keywords: Echinococcus granulosus, protoscoleces, excretory-secretory antigen, monoclonal antibody, ELISA

Cystic echinococcosis (CE) caused by the metacestode (larval) stage of the tapeworm Echinococcus granulosus (Batsch, 1786) is a zoonosis of global distribution (Moro and Schantz 2008). The mature parasite lives in the small intestine of canids and lays eggs that are excreted in the faeces. Intermediate hosts (domestic and/or wild herbivorous animals) become infected by grazing upon grass contaminated with egg-containing faeces. Humans are accidental intermediate hosts and become infected by ingesting eggs after contact with canids or soil, or by eating egg-contaminated food or water (Pakala et al. 2016).

The larval stage develops mostly in the liver and lungs of mammals. Definitive hosts become infected after consumption of offal from infected intermediate hosts (Siracusano et al. 2009). CE represents a serious animal health concern in many countries, including the independent states of the former Soviet Union, and it is a particular problem in Central Asia. In southern Kazakhstan, prevalence in sheep and camels reaches $40-68 \%$ and $43 \%$, respectively, and in cattle the prevalence was half of that in sheep (Baitursunov et al. 2004). CE causes much economic damage due to increased mortality, forced slaughter, decreased productivity, loss of body weight, reduced breeding value and high costs of sanitary measures (Bessonov 2007).

In addition, the disease has great social significance, because infected animals are the key element that maintain the life cycle of the parasite in endemic areas. Human CE is found in all regions of Kazakhstan and the epidemiological situation remains very tense (Shapieva 2011). Hence, the timely diagnosis of CE in domestic animals is a very important part of the eradication program, but ante mortem diagnosis of the disease is difficult because it has no specific clinical symptoms. Therefore, indirect methods based on the detection of serum antibodies against highly specific antigens of the pathogen are of great diagnostic significance. The choice of an appropriate antigen is a crucial point in the improvement of the diagnostic tests for echinococcosis, and such antigen must be based on the developmental stage of this tapeworm (Carmena et al. 2006).

The most common antigens used for serological diagnosis of CE are the total and/or single proteins of hydatid cyst fluid (HCF), collected from infected animals. HCF is a rich reservoir of excretory-secretory antigens (ES-Ag) of protoscoleces containing a wide range of proteins from both parasite and host origin (Aziz et al. 2011). Over the last five years a number of immunodiagnostic tests based on HCF and its individual components such as $\mathrm{AgB}$ as well as $\mathrm{Ag} 5$ were developed for serodiagnosis of human CE (Tawfeek et al. 2011, Mohammadzadeh et al. 2012, Pagnozzi et al. 2014). However, their efficacy in the diagnosis of human hydatid disease remains low (Sarkari and Rezaei 2015). This is due to the presence of large amounts of host pro-

Address for correspondence: A.K. Bulashev, Faculty of Veterinary and Livestock Technology, S. Seifullin Kazakh Agro-Technical University, Prospect Pobedy 62, 010011, Astana, Kazakhstan. Phone:+7 71723175 47; Fax:+7 71723160 72; E-mail: aytbay57@mail.ru 
teins in HCF reducing the specificity (Chemale et al. 2003, Monteiro et al. 2010). There is also a lack of standardisation of the target antigen (Sarkari and Rezaei 2015).

Only a few articles describing the use of HCF antigens in the diagnosis of $\mathrm{CE}$ in domestic herbivores were published during the last 15 years. For instance, antigen B partially purified from HCF of camels or sheep naturally infected with $\mathrm{CE}$ as well as its recombinant analogue were used in the enzyme-linked immunosorbent assay (ELISA) to test sera from slaughtered camels (Ibrahem et al. 2002). Antigenic characteristics of HCF in sheep were investigated by sodium dodecyl sulfate-polyacrylamide gel electrophoresis (SDS-PAGE), and the efficiency of ELISA and enzyme-linked immunoelectrotransfer blot assay were evaluated for diagnosis of sheep hydatidosis (Simsek and Koroglu 2004).

Total HCF was the antigen preparation of greatest value for developing a sensitive, specific and accessible method for diagnosing CE in naturally infected sheep (Gatti et al. 2007). The non-cross reactive $8 \mathrm{kDa}$ protein was prepared from HCF by DEAE-Sepharose fast flow anion exchange chromatography to develop lateral flow technique for immunodiagnosis of CE in sheep (Jeyathilakan et al. 2011). However, to date the value of proteins of protoscoleces and/or its individual components devoid of host antigens for diagnosis of $\mathrm{CE}$ in cattle has not been explored. Moreover, serological diagnosis of $\mathrm{CE}$ in herbivores is difficult because the causative agent of cysticercosis cysticercus tenuicollis (metacestode of Taenia hydatigena Pallas, 1766) share antigenic determinants with the protoscoleces of E. granulosus (see Carmena et al. 2005, Morel et al. 2013, Bulashev et al. 2016a).

The aim of this research was to obtain a monoclonal antibody $(\mathrm{MAb})$ that recognises specifically ES-Ag proteins of in vitro reared protoscoleces of E. granulosus and evaluate its usefulness as capture antibody in a sandwich ELISA (s-ELISA) for the serological diagnosis of cattle CE.

\section{MATERIALS AND METHODS}

Protoscoleces. Fertile hydatid cysts from the liver and lungs were collected during the slaughter of 108 cows from endemic areas in Altyn Taga abattoir (Khosshy village, Akmola region, Kazakhstan). Samples were placed in a sterile container with a tightly fitting lid and delivered to the laboratory for isolation of protoscoleces.

Preparation of ES-Ag. Protoscoleces were settled by gravity, washed several times in phosphate-buffered saline (PBS, $\mathrm{pH}$ 7.2-7.4), and immediately cultured. Viability was evaluated by flame cell motility and general contractile movements (Smyth and Davies 1974, Howel 1986). To obtain ES-Ag, protoscoleces with viability more than $90 \%$ were selected and they were cultured as previously described (Carmena et al. 2004), with some modifications. Briefly, protoscoleces in an amount of 5,000 protoscoleces $/ \mathrm{ml}$ were cultured in $10 \mathrm{ml}$ of incomplete Minimum Essential Medium Eagle (Sigma-Aldrich, St. Louis, USA) supplemented with Penicillin 105 IU/L (Simbirsk Veterinary Company, Ulyanovsk, Russia), Streptomycin 100 IU/L (Joint-Stock Company, Himfarm, Shymkent, Kazakhstan) in $5 \% \mathrm{CO}_{2}$ at $37^{\circ} \mathrm{C}$. The entire supernatants containing ES-Ag of protoscoleces were removed every $8 \mathrm{~h}$ within their first $48 \mathrm{~h}$ of culture in vitro and replaced with the same volume of fresh medium. Before each medium change, the viability of the parasite larvae was determined as described above. The collected supernatants were concentrated using PEG 6000 (Sigma-Aldrich), and it was used as protoscolex ES-Ag. ES-Ag from cysticercus tenuicollis was similarly prepared. ES-Ag of the trematode Opisthorchis felineus (Rivolta, 1884), obtained in our previous studies (Bulashev et al. 2011), was used in the present research.

Preparation of somatic antigens (S-Ag). S-Ag of protoscoleces, isolated from cattle hepatic hydatid cysts, was obtained according to the method described in Carmena et al. (2005). $\mathrm{S}-\mathrm{Ag}$ of two trematode species, O. felineus and/or Metorchis bilis (Braun, 1790) (both Opisthorchiidae), was prepared as previously described (Borovikov et al. 2010). The protein concentration was determined using the method of Bradford (1976).

Serum samples. The whole blood was collected from cattle before slaughtering in a tube, covered and left undisturbed at room temperature to clot for $30 \mathrm{~min}$. The clot was removed by centrifugation at $1,000 \mathrm{~g}$ for $10 \mathrm{~min}$ in a refrigerated centrifuge. The supernatant (serum) was transferred into a clean polypropylene tube using a Pasteur pipette. A portion of serum was divided into $0.5 \mathrm{ml}$ aliquots and stored at $-70^{\circ} \mathrm{C}$.

Obtaining MAb. Balb/c mice were given intraperitoneal injections of $0.1 \mathrm{mg}$ of protoscolex ES-Ag in $0.1 \mathrm{ml}$ of incomplete Freund's adjuvant (Sigma-Aldrich) on the first day of immunisation. Then, on days 7, 11, 12 and 13, mice were injected with $0.1 \mathrm{mg}$ antigen in PBS, $\mathrm{pH}$ 7.2-7.4. Three days after the last immunisation, mice were bled from the tail vein into microfuge tubes (Isolab, Wertheim, Germany). Blood was centrifuged at $1,000 \mathrm{~g}$ for $10 \mathrm{~min}$ and antiserum was transferred to a clean tube.

The serum antibody titres were determined by indirect ELISA (i-ELISA). The assay was carried out in flat-bottomed 96-well microtitre plates (Corning Inc., New York, USA). Briefly, the wells were filled with protoscolex ES-Ag $(5.0 \mu \mathrm{g} / \mathrm{ml})$ in bicarbonate buffer (BCB, pH 9.6). Serum samples were diluted in PBS, pH 7.2-7.4, with $0.05 \%$ Tween-20 (PBS-T) starting with 1 : 100. Immune complexes were revealed by using peroxidase-conjugated goat anti-mouse $\operatorname{IgG}(\mathrm{H}+\mathrm{L})$ (Jackson Immuno Research, West Grove, USA) and 3.3',5.5'-tetramethylbenzidine (Sigma-Aldrich). The optical density (OD) value was obtained by reading the reaction at $492 \mathrm{~nm}$ using a microtitre plate reader (Asys Hitech GmbH, Eugendorf, Austria).

Hybridomas were obtained by fusion of X63-Ag8.653 myeloma cells and lymphocytes of immunised mice with high titres of antibodies to protoscolex ES-Ag using polyethylenglycol 4000 (Fluka BioChemika, Buchs, Switzerland) according to the method of Köhler and Milstein (1975). The fusion mixture was directly distributed onto 96-well culture plates (PRS Panreac, Castellar del Valles, Barcelona, Spain) with feeder cells containing HAT-medium (Sigma-Aldrich). For culturing hybridomas, RPMI-1640 medium containing 1M HEPES, 200 mM L-glutamine, $100 \mathrm{mM}$ sodium pyruvate, and $10 \%$ of heat inactivated fetal calf serum was used (all from Sigma-Aldrich).

Hybridomas were tested for antibody production by assaying their supernatants between 10 and 20 days post-fusion. i-ELISA was used to determine the clones producing MAb against protoscolex ES-Ag. Hybridomas were considered positive if the supernatant OD value was higher at least twice the OD value of the 
control culture fluid obtained from the myeloma cells. Selected crude clones were sub-cloned by limiting dilution (Waldmann and Lefkovits 1984).

Preparative amounts of MAb were obtained by culturing hybridoma clones in the intraperitoneal cavity of syngeneic mice pretreated with pristane (Sigma-Aldrich). Ascitic fluid was cleared by centrifugation and MAb were sequentially purified by ammonium sulfate precipitation (Appli Chem Panreac ITW Companies, Darmstadt, Germany) and gel filtration chromatography.

Immunoglobulin classes of MAb were determined by i-ELISA using Mouse Monoclonal Antibody Isotyping Reagents (Sigma-Aldrich). Antibody affinity was established by a non-competitive immunoassay as described previously (Beatty et al. 1987).

SDS-PAGE and western blot. SDS-PAGE $(12.5 \%$ gel concentration) was performed as described by Laemmli (1970) and proteins of protoscolex ES-Ag were visualised by Coomassie blue staining. The molecular mass of the protein bands was determined by the software Photo-Capt, Version 12.4 (Vilber Lourmat). After electrophoresis, proteins were transferred onto nitrocellulose membrane (Watman Nytran Supercharge Aldrich, St. Louis, USA) and immunoblotting was carried out as described by Towbin et al. (1979). After blocking in a solution of $1 \%$ BSA overnight at $4{ }^{\circ} \mathrm{C}$, the nitrocellulose membrane was incubated with $\mathrm{MAb}$ at room temperature for $1.5 \mathrm{~h}$. Peroxidase-conjugated goat anti-mouse $\operatorname{IgG}$ (Sigma-Aldrich) was used at $1: 1,000$ dilution in PBS-T at $37^{\circ} \mathrm{C}$ for $1 \mathrm{~h}$ for detection of antigen-antibody complexes. The latter was developed with 4-chloro-1-naphthol (Sigma-Aldrich). Due to ES-Ag limitations, myeloma cell's supernatant was tested in parallel by immunodot blot technique (Salazar-Anton et al. 2012).

Sandwich ELISA for the detection of cow's antibodies against ES-Ag (s-ELISA/ES-Ag) and/or S-Ag of protoscoleces (s-ELISA/S-Ag). Briefly, a 96-well microtitre plate was coated with $\mathrm{MAb}(5.0 \mu \mathrm{g} / \mathrm{ml})$ in $\mathrm{BCB}(\mathrm{pH} 9.6)$ at $4{ }^{\circ} \mathrm{C}$ overnight. After washing with PBS-T three times, the remaining binding sites of the wells were blocked with $1 \%$ BSA and the appropriate antigen was added. Non-specifically bound components were removed by washing and serum samples were applied. The presence of specific antibodies was detected using peroxidase-conjugated rabbit anti-bovine IgG (whole molecule) (Sigma-Aldrich). Pooled sera from healthy cows were used as control. ELISA results were considered positive if the OD value of the well with test animal serum was higher at least twice the OD value of the control well.

Indirect ELISA for the detection of cow's antibodies against protoscolex S-Ag (i-ELISA/S-Ag). A microtitre plate was filled with S-Ag $(5.0 \mu \mathrm{g} / \mathrm{ml})$ in $\mathrm{BCB}(\mathrm{pH}$ 9.6). After incubation at $37^{\circ} \mathrm{C}$ for $1 \mathrm{~h}$, the plate was sequentially washed with PBS and PBS-T, blocked by $1 \%$ BSA, and incubated in the same mode. After another wash, serum sample was added and the plate was incubated at $37^{\circ} \mathrm{C}$ for $1 \mathrm{~h}$. After washing, peroxidase-conjugated rabbit anti-bovine IgG (whole molecule) (Sigma-Aldrich) was added and allowed to react with its antigen under the same condition. Finally, absorbance readings were taken in a microtitre plate reader as mentioned above.

The specificity and sensitivity of the ELISA tests were calculated using formulas: specificity $=$ positive test results with fertile cysts/positive test results with all types of cysts $\times 100$; sensitivity $=$ positive test results with all types of cysts/number of cattle with all types of cysts $\times 100$.

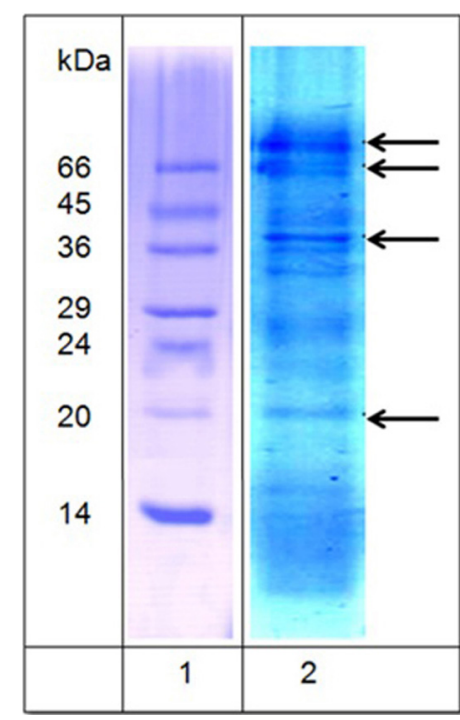

Fig. 1. SDS-PAGE of culture supernatant containing ES-Ag produced by protoscoleces of Echinococcus granulosus (Batsch, 1786) from a liver cyst during their first $48 \mathrm{~h}$ of culture. Molecular mass markers are expressed in $\mathrm{kDa}$ and are indicated on the left. The arrows on the right point to four major proteins with molecular mass $76.5 \mathrm{kDa}, 68.2-66.0 \mathrm{kDa}, 37.8 / 35.2 \mathrm{kDa}$ and $20.6 \mathrm{kDa}$.

Hybridoma strain MAb/3B1-HD has been deposited in the Republic's Collection of Microorganisms, the Ministry of Education and Science of the Republic of Kazakhstan (010000, Astana, Sh. Valikhanov Street 43) under the registration number C-RKM 0360. It is available for transfer to third parties through a material transfer agreement.

\section{RESULTS}

The final concentration of protoscolex ES-Ag before each change of medium was in the range of $15-30 \mu \mathrm{g} / \mathrm{ml}$. SDS-PAGE electrophoresis of ES-Ag showed the presence of nine protein bands with molecular mass between 19.5-76.5 kDa (Fig.1). Among them there were four major proteins with molecular mass of $76.5 \mathrm{kDa}, 68.2-66.0 \mathrm{kDa}$, $37.8 / 35.2 \mathrm{kDa}$ and $20.6 \mathrm{kDa}$. Minor proteins had molecular mass of $43.6 \mathrm{kDa}, 40.9 \mathrm{kDa}, 32.2 \mathrm{kDa}, 26.3 \mathrm{kDa}$ and $19.5 \mathrm{kDa}$, respectively.

Three hundred twenty-seven hybridomas were obtained as a result of three hybridisations of myeloma cells and lymphocytes, stimulated with ES-Ag of in vitro reared protoscoleces. Based on ELISA tests using antigens of cysticercus tenuicollis, Metorchis bilis and Opistorchis felineus, two clones producing MAb specific to Echinococcus granulosus were selected. The selected clones were subjected to sub-cloning and one of the clones from each hybridoma with maximum antibody activity was selected for further study (Table 1).

For research purposes, MAb 3B1 is more suitable as a capture antibody for s-ELISA than MAb 3C10, because being a pentamer it has a relatively higher affinity for its antigen. To detect the protein of protoscoleces that is recognised specifically by MAb 3B1 the same samples of ES$\mathrm{Ag}$ analysed by SDS-PAGE were also tested by western blot. (Fig. 2). 
Table 1. Characterisation of selected hybridomas.

\begin{tabular}{|c|c|c|c|c|c|c|}
\hline \multirow{2}{*}{$\begin{array}{l}\text { Designation of } \\
\text { hybridomas }\end{array}$} & \multirow{2}{*}{ MAb isotypes } & \multirow{2}{*}{ MAb affinity } & \multicolumn{2}{|c|}{ Productivity of hybridomas $(\mathrm{mg} / \mathrm{ml})$} & \multicolumn{2}{|c|}{$\begin{array}{l}\text { MAb titres by ELISA } \\
\text { against protoscolex ES-Ag }\end{array}$} \\
\hline & & & in vitro & in vivo & supernatant & ascites fluid \\
\hline $3 \mathrm{C} 10$ & $\operatorname{IgG} 2 \mathrm{a}$ & $1.7 \times 10^{-8}$ & 0.063 & 2.0 & $1: 64$ & $1: 12,800$ \\
\hline 3B1 & $\operatorname{IgM}$ & $7.7 \times 10^{-8}$ & 0.125 & 4.0 & $1: 128$ & $1: 25,600$ \\
\hline
\end{tabular}

$\mathrm{MAb}$ - monoclonal antibody; ELISA - enzyme-linked immunosorbent assay; Es-Ag - excretory-secretory antigen.

Table 2. Necropsy and serological testing of cattle for cystic echinococcosis $(n=108)$.

\begin{tabular}{|c|c|c|c|c|c|}
\hline \multirow{4}{*}{ Types of organ damage } & \multirow{4}{*}{ Affected organs } & \multirow{4}{*}{ Number of cows } & \multicolumn{3}{|c|}{ Positive $(+)$ and negative results (-) of serological investigation } \\
\hline & & & s-ELISA & s-ELISA & i-ELISA \\
\hline & & & \multicolumn{3}{|c|}{ Antigens of protoscoleces } \\
\hline & & & ES-Ag & S-Ag & S-Ag \\
\hline \multirow{3}{*}{ Fertile cysts } & liver & 2 & + & + & + \\
\hline & lungs & 5 & + & + & + \\
\hline & liver + lungs & 1 & + & + & + \\
\hline \multirow{6}{*}{ Acephalocysts } & liver & 1 & - & - & - \\
\hline & lungs & 3 & - & - & - \\
\hline & liver + lungs & 1 & - & - & + \\
\hline & liver + lungs & 1 & + & + & - \\
\hline & liver + lungs & 1 & - & + & + \\
\hline & liver + lungs & 1 & - & - & - \\
\hline \multirow{4}{*}{ Calcified foci } & liver & 1 & - & - & - \\
\hline & liver & 1 & + & + & + \\
\hline & lungs & 1 & - & - & - \\
\hline & lungs & 2 & - & - & + \\
\hline \multirow{2}{*}{ Tubercular foci } & lungs & 1 & - & - & + \\
\hline & lungs & 1 & - & - & - \\
\hline \multicolumn{2}{|c|}{ The absence of visible lesions of the internal organs } & 1 & - & - & + \\
\hline \multicolumn{2}{|c|}{ Sensitivity } & & $48 \%$ & $52 \%$ & $62 \%$ \\
\hline \multicolumn{2}{|l|}{ Specificity } & & $80 \%$ & $73 \%$ & $53 \%$ \\
\hline
\end{tabular}

s-ELISA - sandwich enzyme-linked immunosorbent assay; i-ELISA - indirect enzyme-linked immunosorbent assay; Es-Ag - excretory-secretory antigen; S-Ag - somatic antigen.

Immunoblotting analyses showed the specificity of $\mathrm{MAb} 3 \mathrm{~B} 1$ to the epitope of a protein with a apparent molecular mass of $20.6 \mathrm{kDa}$. No reactivity was detected against protoscolex ES-Ag by immunodot blot technique using a supernatant from myeloma cells (data not shown). MAb 3B1 has been used in s-ELISA/ES-Ag and s-ELISA/S-Ag for selective sensitisation of the solid phase with protoscolex-specific protein to study the presence of antibodies in 108 cows from endemic area in comparison with i-ELISA/S-Ag (Table 2).

As shown in Table 2, CE was observed $24 \%$ only in liver, $52 \%$ only in lungs and $24 \%$ in both liver and lungs. Using s-ELISA/ES-Ag allowed to detect 10 samples of blood serum $(9 \%)$ containing specific antibodies. s-ELISA/S-Ag confirmed all the positive results of the s-ELISA/ES-Ag and additionally identified one more cow with serum antibodies to protoscoleces. The results of i-ELISA/S-Ag identified 15 serologically positive cows (14\%).

Table 2 shows that the most reliable results were obtained by using s-ELISA/ES-Ag. For example, cows having CE-specific lesions in the organs reacted serologically positive and eight of the animals had fertile cysts. The presence of specific antibodies has also been detected in

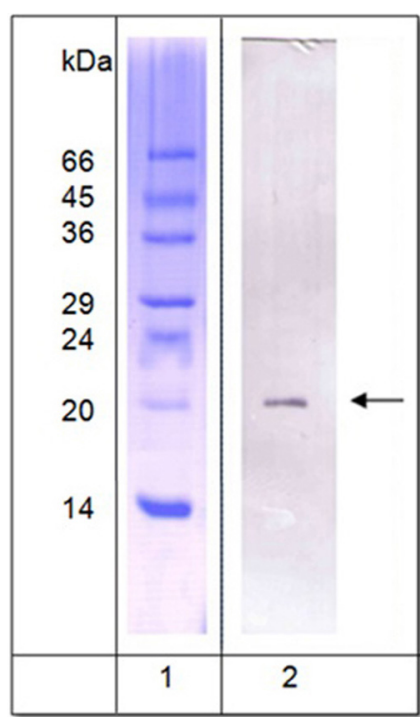

Fig. 2. Western blot using MAb 3B1 to protoscolex ES-Ag. Proteins separated by SDS-PAGE were transferred electrophoretically onto nitrocellulose membranes and probed with MAb 3B1. Molecular mass markers are expressed in $\mathrm{kDa}$ and are indicated on the left. The arrow on the right points to ES-Ag with molecular mass $20.6 \mathrm{kDa}$ that reacts with MAb 3B1. 
two animals, one of which had acephalocysts and another calcified cysts. It should be noted that acephalocysts were found in a cow that gave additional positive result by s-ELISA/S-Ag.

The specificity of i-ELISA/S-Ag was low in comparison with its sandwich variants. For example, in two cases false positive results were obtained in cows with tubercular foci and/or without visible lesions in their internal organs. Moreover, the presence of antibodies was proven in the sera of two and three heads with acephalocysts and calcified cysts, respectively. It should be noted that the average antibody titre of eight cows with fertile cysts was significantly higher $(1: 3,200-1: 6,400)$ compared with 10 analogs having cropped invasion foci $(1: 400-1: 800)$. In total, sensitivity and specificity of s-ELISA were determined as $48 \%, 52 \%$ and $73 \%, 80 \%$, respectively, whereas corresponding rates for i-ELISA were $62 \%$ and $53 \%$, respectively.

\section{DISCUSSION}

Several serological tests based on HCF and its immunogenic components have been developed recently for diagnosing human CE (Tawfeek et al. 2011, Mohammadzadeh et al. 2012, Jin et al. 2013, Pagnozzi et al. 2014). Unfortunately, the immunological tests available today are not satisfactory and approaches to the serological diagnosis of $\mathrm{CE}$ are still the subject of discussion (Sarkari and Rezaei 2015). Only a few papers are devoted to the use of HCF and its partially purified proteins in the diagnosis of $\mathrm{CE}$ in camels (Ibrahem et al. 2002) and sheep (Simsek and Koroglu 2004, Gatti et al. 2007, Jeyathilakan et al. 2011). It is known that the presence of large amounts of host proteins in the HCF significantly interferes with identification of the parasite specific proteins (Chemale et al. 2003, Monteiro et al. 2010).

In this regard, supernatants of in vitro reared protoscoleces is a promising source for obtaining its ES-Ag free of host contaminants. Unfortunately, very little information is available about using this type of antigen for diagnostic purposes. The results related to the detection of antibodies in the blood of infected dogs against ES-Ag of in vitro reared protoscoleces were described (Carmena et al. 2005). ES-Ag obtained from the first $50 \mathrm{~h}$ maintenance of protoscoleces in culture medium was also tested for immunodiagnosis of human CE (Carmena et al. 2004) and the immune responses of Balb/c mice to the adult tapeworm antigens cultured in vitro were also investigated (Rahimi et al. 2011). However, the diagnostic value of protoscolex ES-Ag, isolated from its cultural medium, in detecting specific antibodies in herbivores, particularly in cattle, remains unexplored.

Recent findings of proteomic analysis of excretory/secretory products of protoscoleces show the complexity of their protein composition. Thirty two proteins, including 18 that were never detected previously in ES-Ag from in vitro culture of E. granulosus, have been identified by liquid chromatography-mass spectrometry proteomic analysis, and such an approach would be useful to identify some proteins that cannot be detected in HCF because of their small content in comparison to major parasite and host
HCF components (Veridiana et al. 2012). In this context, it is very important to isolate an immunogenic protein specific for protoscoleces from the total ES-Ag in developing reliable serological tests for the diagnosis of CE.

The results of our studies showed that protoscoleces release in vitro 9 detectable components ranging 19.5-76.5 kDa. We identified the proteins with apparent molecular mass of $20.6 \mathrm{kDa}, 32.2 \mathrm{kDa}, 35.2 / 37.8 \mathrm{kDa}$ and $43.6 \mathrm{kDa}$ that were previously described in the composition of ES-Ag obtained during the first $50 \mathrm{~h}$ of culture (Carmena et al. 2004). It was found that different cultures of secrete proteins of liver protoscoleces with molecular mass between $10 \mathrm{kDa}$ and $98 \mathrm{kDa}$ with major bands of $90 \mathrm{kDa}$, $69 \mathrm{kDa}, 34 \mathrm{kDa}, 21 \mathrm{kDa}, 16 \mathrm{kDa}$ and $13 \mathrm{kDa}$, as well as doublets of 43/47 kDa, 35/38 kDa and 29/31 kDa and a triplet of $55 / 65 \mathrm{kDa}$. According to the authors' suggestion various ecological loads stimulate parasites to secrete a variety of metabolites.

We obtained two clones of Mab (IgM and $\operatorname{IgG}$ ) against ES-Ag of in vitro reared protoscoleces of E. granulosus, namely $3 \mathrm{C} 1$ and $3 \mathrm{~B} 1$. Antibody avidity depends on affinity as well as the number of antigen binding sites, and in the case of equal affinity, $\operatorname{IgM}$ is superior as it is a pentamer (Khaitov 2011). Therefore, we used MAb 3B1 in s-ELISA as capture antibody for the sensitisation of the solid phase with specific protein of protoscoleces to determine serum antibodies of cows that are infected with CE. This MAb was specific to an epitope of ES-Ag protein with molecular mass of $20.6 \mathrm{kDa}$. The diagnostic value of a protein with the same molecular mass, as well as proteins of $89 \mathrm{kDa}$, $74 \mathrm{kDa}, 47 / 50 \mathrm{kDa}, 32 \mathrm{kDa}$ was previously established during evaluation of protoscolex ES-Ag potential for immunodiagnosis of human CE (Carmena et al. 2004).

Early attempts to develop serological tests on the basis of MAb to antigens of E. granulosus proved unsuccessful for the diagnosis of CE in sheep (Craig et al. 1980). Purification of natural antigens with specific antibodies or affinity depletion of related antigens with MAb only partially reduced the problems associated with cross-reactivity (Craig and Rickard 1981, Craig et al. 1981, Lightowlers et al. 1984). Furthermore, research information devoted to obtaining and using of MAb against the adult parasite is very rare. For instance, biotinylated MAb produced against somatic extract of adult Echinococcus multilocularis (Leuckart, 1863) was used in ELISA for coproantigen detection in dogs experimentally and naturally infected with E. granulosus (see Malgor et al. 1997). Two MAb have been obtained against ES-Ag of adult E. granulosus that recognised a $50 \mathrm{kDa}$ antigen in the somatic extract and an $85 \mathrm{kDa}$ component in the ES-Ag. They were used as detecting antibodies in developing coproantigen capture ELISA (Casaravilla et al. 2005).

In the present study the principle of finding specific antibodies in cattle serum by s-ELISA was based on the selective sensitisation of the solid phase with the $20.6 \mathrm{kDa}$ protein from ES-Ag and/or S-Ag of protoscoleces by $\mathrm{MAb}$. First of all, the plate was sensitised with MAb 3B1. After blocking active sites of the wells ES-Ag and/or S-Ag were applied. Then non-specific antigens were removed by 
washing and then cattle serum samples were added. The presence of specific antibodies was detected by using anti-bovine conjugate.

The diagnostic value of three variants of ELISA was tested on cattle from CE endemic area in comparison with necropsy. The results of necropsy of cattle showed that 21 cows $(19 \%)$ were infected with $\mathrm{CE}$ and fertile cysts were found in liver, lungs and both of organs of $8(38 \%)$ heads. It should be noted that the lungs were the predominant sites of the CE in cattle as already reported (Beyhan and Umur 2011).

The sensitivity of s-ELISA/ES-Ag, s-ELISA/S-Ag and i-ELISA/S-Ag in detecting animals infected with CE was $48 \%, 52 \%$ and $62 \%$, respectively. Low levels of sensitivity of the used ELISA was due to the fact that 13 cows according to necropsy had sterile cysts and calcified foci. The relatively high specificity $(80 \%)$ in detection of fertile cysts has been observed in the case of using s-ELISA/ES-Ag. The last test also found the presence of antibodies in the serum of two cows that have recovered from the disease according to the necropsy results.

Apparently, serum antibodies of these animals have not been cleared yet from the bloodstream by the time of serological investigation. This hypothesis was supported by significantly higher antibody titres measured by ELISA in cows having fertile cysts $(n=8)$ than in those having sterile cysts or calcified lesions $(n=10)$.

The sensitivity of s-ELISA/S-Ag (52\%) was slightly higher than that of s-ELISA/ES-Ag (48\%). However, this was compensated by their specificity $(73 \%$ and $80 \%$, respectively), because s-ELISA/S-Ag additionally identified a cow with hepato-pulmonar sterile cysts. i-ELISA/S-Ag showed relatively high sensitivity $(62 \%)$, but its specificity was quite low (53\%). It gave false positive results in testing sera from a healthy animal and a cow with tubercular foci.

The relatively high reliability of s-ELISA/ES-Ag in the identification of animals with the fertile cysts may be explained by coating solid phase with specific protein of protoscoleces by means of MAb. The main obstacle for using the proposed test in practice is the difficulty of ob- taining ES-Ag in sufficient quantity. In our opinion, there are three approaches to address this issue. First the replacement of ES-Ag with S-Ag is possible, because the last preparation is easy to obtain, and protoscolex protein with molecular mass $20.6 \mathrm{kDa}$ is available in the composition of both antigens. The second approach is to use anti-idiotypic antibodies (AIab), representing 'internal images' of the antigen epitopes. The suitability of monoclonal AIab has been shown in detecting antibodies against blood fluke Schistosoma japonicum (Katsurada, 1904) in human sera (Wu et al. 1993). The possibility of using AIab as an alternative immunoreagent was shown in bovine cysticercosis (Hayunga et al. 1992). In our previous research, we have used an indirect-ELISA and a competitive-ELISA based on using AIab specific for MAb against the excretory-secretory protein of $O$. felineus with a molecular mass of $28 \mathrm{kDa}$ for the detection of antibodies in sera of dogs experimentally infected with opisthorchiasis (Bulashev et al. 2016b). Substitution of parasite antigen with AIAb avoids the use of infected animals, reduces time-consuming steps of antigen preparation and allows to obtain standardised antigens. The third approach is determining the sequence of the $20.6 \mathrm{kDa}$ protein and its production by recombinant DNA technology or designing synthetic peptides derived from its sequence for diagnostic purposes.

Thus, ES-Ag from in vitro reared protoscoleces of E. granulosus contains a potential diagnostic antigen with a molecular mass of $20.6 \mathrm{kDa}$; it can be used in the serological diagnosis of CE. However, further studies will be necessary to define more precisely the value of the results we report here. This is because the period of antibody elimination from the bloodstream of recovered cattle still remains uninvestigated. The solution of this problem will help improve the specificity of the proposed test during the second serological testing of cattle for CE.

Acknowledgements. The authors express their gratitude to Maksim Sutula and Bakhyt Shakizhanova for providing technical assistance in taking blood samples from animals and collecting hydatid cysts from infected ones.

\section{REFERENCES}

Aziz A., Zhang W., Li J., Loukas A., McManus D.P., MulVENNA J. 2011: Proteomic characterisation of Echinococcus granulosus hydatid cyst fluid from sheep, cattle and humans. J Proteomics 74: 1560-1572.

Baitursunov K.K., Shaikenov B.Sh., Abdybekova A.M. 2004: Distribution of Echinococcus amongst agricultural animals in Kazakhstan. In: P. Torgerson and B. Shaikenov (Eds.), Echinococcosis in Central Asia: Problems and Solutions. Dauir, Zurich-Almaty, pp. 101-118.

Beatty J.D., Beatty B.G., Vlahos W.G. 1987: Measurement of monoclonal antibody affinity by non-competitive enzyme immunoassay. J. Immunol. Methods 100: 173-179.

Bessonov A.S. (Ed.) 2007: [Cystic Hydatid Disease]. JSC Locus Standi, Moscow, 672 pp. (In Russian.)

BEYHAN Y.E., UMUR S. 2011: Molecular characterization and prevalence of cystic echinococcosis in slaughtered water buffaloes in Turkey. Vet. Parasitol. 181: 174-179.

Borovikov S.N., Koybagarov M.A., Suranshiev Zh.A., Baesheva D.A., Atygaeva S.K., Khalikova A.S. 2010: [Prepa- ration and study of immunochemical properties of Opisthorchis felineus antigens] Biotech. Theory Pract. 4: 70-74. (In Russian.) BRADFORD M. 1976: A rapid and sensitive method for the quantitation of microgram quantitates of protein utilizing the principle of protein-dye binding. Anal. Biochem. 72: 248-225.

Bulashev A.K., Akibekov O., Tokpan S., Serikova S., AbulGAZImova G. 2016a: Hematological and serological investigation of dogs during experimental echinococcosis. Cardiovasc. Hematol. Agents Med. Chem. 14: 59-67.

Bulashev A.K., Borovikov S.N., Koybagarov M.A., SuranShiev Zh.A., Lider L.A., Baesheva D.A., Atygaeva S.K., Serikova Sh., Khalikova A.S., Sutula M.Y. 2011: Inventor; S. Seifullin Kazakh Agro-Technical University, assignee. [Method of preparation of excretory-secretory antigen for serological diagnosis of opisthorchiasis.] Republic of Kazakhstan patent KZ 68176. (In Russian.)

Bulashev A.K., Borovikov S.N., Serikova S.S., Suranshiev Z.A., Kiyan V.S., Eskendirova S.Z. 2016b: Development of 
an ELISA using anti-idiotypic antibody for diagnosis of opisthorchiasis. Folia Parasitol. 63: 025.

Carmena D., Benito A., Eraso E. 2006: Antigens for the immunodiagnosis of Echinococcus granulosus infection: an update. Acta Trop. 98: 74-86.

Carmena D., Benito A., Martínez J., Guisantes J.A. 2005 Preliminary study of the presence of antibodies against excretory-secretory antigens from protoscoleces of Echinococcus granulosus in dogs with intestinal echinococcosis. Mem. Inst. Oswaldo Cruz. 100: 311-317.

Carmena D., Martinez J., Benito, A., Guisantes J.A. 2004 Characterization of excretory-secretory products from protoscoleces of Echinococcus granulosus and evaluation of their potential for immunodiagnosis of human cystic echinococcosis. Parasitology 129: 371-378.

Casaravilla C., Malgor R., Rossi A., Sakai H., Nonaka N., Kamiya M., Carmona C. 2005: Production and characterization of monoclonal antibodies against excretory/secretory products of adult Echinococcus granulosus, and their application to coproantigen detection. Parasitol. Int. 54: 43-49.

Chemale G., van Rossum A.J., Jefferies J.R., Barrett J., Brophy P.M., Ferreira H.B., Zaha A. 2003: Proteomic analysis of the larval stage of the parasite Echinococcus granulosus: causative agent of cystic hydatid disease. Proteomics 3: 1633-1636.

Craig P.S., Hocking R.E., Mitchell G.F., Rickard M.D. 1981: Murine hybridoma-derived antibodies in the processing of antigens for the immunodiagnosis of hydatid (Echinococcus granulosus) infection in sheep. Parasitology 83: 303-317.

Craig P.S., Mitchell G.F., Cruise K.M., Rickard M.D. 1980: Hybridoma antibody immunoassays for the detection of parasitic infection: attempts to produce an immunodiagnostic reagent for a larval taeniid cestode infection. Aust. J. Exp. Biol. Med. Sci. 58: 339-350.

Craig P.S., Rickard M.D. 1981: Studies on the specific immunodiagnosis of larval cestode infections of cattle and sheep using antigens purified by affinity chromatography in any enzyme-linked immunosorbent assay (ELISA). Int. J. Parasitol. 11: 441-449.

Gatti A., Alvarez A.R., Araya D., Mancini S., Herrero E., Santillan G., LarRieu E. 2007: Ovine echinococcosis: I. Immunological diagnosis by enzyme immunoassay. Vet. Parasitol. 143: $112-121$.

Hayunga E.G., Sumner M.P., Duncan J.F. Jr., Chakrabarti E.K., Webert D.W. 1992: Production of anti-idiotypic antibodies as potential immunoreagents for the serological diagnosis of bovine cysticercosis. Ann. N. Y. Acad. Sci. 653: 178-183.

Howel M.J. 1986: Cultivation of Echinococcus species in vitro. In: R.C.A. Thompson (Ed.), The Biology of Echinococcus and Hydatid Disease. George Allen \& Unwin, London, pp. 143-163.

Ibrahem M.M., Rafiei A., Dar F.K., Azwai S.M., Carter S.D., Craig P.S. 2002: Serodiagnosis of cystic echinococcosis in naturally infected camels. Parasitology 125: 245-251.

Jeyathilakan N., Abdul Basith S., John L., Chandran N.D., RAJ G.D. 2011: Development and evaluation of flow through technique for diagnosis of cystic echinococcosis in sheep. Vet. Parasitol. 180: 250-255.

Jin Y., Anvarov K., Khajibaev A., Hong S., Hong S.T. 2013 Serodiagnosis of echinococcosis by ELISA using cystic fluid from Uzbekistan sheep. Kor. J. Parasitol. 51: 313-317.

Khaitov R.M. (Ed.) 2011: [Immunology.] GEOTAR-Media, Moscow, 528 pp. (In Russian.)

KöHler G., Milstein C. 1975: Continuous cultures of fused cells secreting antibody of predefined specificity. Nature 256: 495 497.

LAemmLi U.K. 1970: Cleavage of structural proteins during the assembly of the head of bacteriophage T4. Nature 227: 680-685.

Lightowlers M.W., Rickard M.D., Honey R.D., Obendorf D.L, Mitchell G.F. 1984: Serological diagnosis of Echinococcus granulosus infection in sheep using cyst fluid antigen processed by antibody affinity chromatography. Aust. Vet. J. 61: 101-108.

Malgor R., Nonaka N., Basmadjian I., Sakai H., Carámbula B., OKu Y., Carmona C., Kamiya M. 1997: Coproantigen detection in dogs experimentally and naturally infected with Echinococcus granulosus by a monoclonal antibody-based enzyme-linked immunosorbent assay. Int. J. Parasitol. 27: 16051612.

Mohammadzadeh T., Sako Y., Sadjuadi S.M., Sarkari B., Iто A. 2012: Comparison of the usefulness of hydatid cyst fluid, native antigen $\mathrm{B}$ and recombinant antigen B8/1 for serological diagnosis of cystic echinococcosis. Trans. R. Soc. Trop. Med. Hyg. 106: 371-375.

Monteiro K.M., de Carvalho M.O., Zaha A., Ferreira H.B. 2010: Proteomic analysis of the Echinococcus granulosus metacestode during infection of its intermediate host. Proteomics 10: 1985-1999.

Morel N., Lassabe G., Elola S., Bondad M., Herrera S., Mari C., Last J., Jensen O., Gonzales G. 2013: A monoclonal antibody-based copro-ELISA kit for canine echinococcosis to support the PAHO effort for hydatid disease controle in south America. PLoS Negl. Trop. Dis. 7: e1967.

Moro P., Schantz P.M. 2008: Echinococcosis: a review. Int. J. Infect. Dis. 13: 125-133.

Pagnozzi D., Biosa G., Addis M.F., Mastrandrea S., Masala G., UzzaU S. 2014: An easy and efficient method for native and immunoreactive Echinococcus granulosus antigen 5 enrichment from hydatid cyst fluid. PLoS ONE 9: e104962.

Pakala T., Molina M., Wu G.Y. 2016: Hepatic echinococcal cysts: a review. J. Clin. Transl. Hepatol. 4: 39-46.

Rahimi H.R., Sarkari B., Mohammadzadeh T., Sadjuadi S.M. 2011: Immune responses to antigens of in vitro reared Echinococcus granulosus adult worms in Balb/c mice. Iran. J. Immunol. 8: 236-243.

Salazar-Anton F., Tellez A., Lindh J. 2012: Evaluation of an immunodot blot technique for the detection of antibodies against Taenia solium larval antigens. Parasitol. Res. 110: 2187-2191.

Sarkari B., Rezaei Z. 2015: Immunodiagnosis of human hydatid disease: where do we stand? World J. Methodol. 5: 185-195.

Shapieva ZH. 2011: About the situation on zoonotic parasitic invasions in Kazakhstan. Proc. Int. Conf. "Zoonotic Infections: Yesterday, Today, Tomorrow". Gylym, Almaty, 24-25 December 2011, pp. 56-59 (In Russian.)

Simsex S., Koroglu E. 2004: Evaluation of enzyme-linked immunosorbent assay (ELISA) and enzyme-linked immunoelectrotransfer blot (EITB) for immunodiagnosis of hydatid diseases in sheep. Acta Trop. 92: 17-24.

Siracusano A., Teggi A., Ortona E. 2009: Human cystic echinococcosis: old problems and new perspectives. Interdiscip. Perspect. Infect. Dis. 2009: 474368.

Smyth J.D. Davies Z. 1974: In vitro culture of the strobilar state of Echinococcus granulosus (sheep strain): a review of basic problems and results. Int. J. Parasitol. 4: 631-644.

Tawfeek G.M., Elwakil H.S., El-Hoseiny L., Thabet H.S., Sarhan R.M., Awad N.S., Anwar W.A. 2011: Comparative analysis of the diagnostic performance of crude sheep hydatid cyst fluid, purified antigen B and its subunit (12 kDa), assessed by ELISA, in the diagnosis of human cystic echinococcosis. Parasitol. Res. 108: 371-376.

Towbin H., Staehelin T., Gordon J. 1979: Electrophoretic transfer of proteins from polyacrylamide gels to nitrocellulose sheets: procedure and some applications. Proc. Natl. Acad. Sci. USA 76: 4350-4354.

Veridiana G.V., Monteiro K.M., Drumond F., de Carvalho M.O., Vargas D.M., Zaha A., Ferreira H.B. 2012: Excretory/secretory products from in vitro-cultured Echinococcus granulosus protoscoleces. Mol. Biochem. Parasitol. 183: 15-22.

WaLdmann H., LefKovits I. 1984: Limiting dilution analysis of cells of the immune system II: what can be learnt? Immunol. Today 5: 295-288. 
Wu Y.Q., TaO R.H., QiU Z.N., LuO Q.P., GuAN X.H., Wu G.L., ZHAO W.X. 1993: [A study on the monoclonal anti-idiotypic an- tibody NP30 for the diagnosis of schistosomiasis japonica.] Par. Doctrine Par. Dis. China 11: 195-197. (In Chinese.)

Cite this article as: Bulashev A.K., Suranshiev Z.A., Akibekov O.S., Akanova Z.Z., Abulgazimova G.A. 2017: Serological diagnosis of cystic echinococcosis in cattle. Folia Parasitol. 64: 005. 